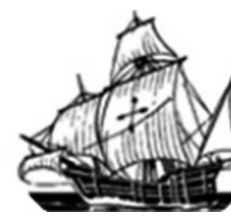

Nau Literária: crítica e teoria de literaturas • seer.ufrgs.br/NauLiteraria

ISSN 1981-4526・PPG-LET-UFRGS • Porto Alegre • vol. 09, n. $01 \bullet$ jan/jun 2013

Dossiê: Voz e Interculturalidade

\title{
JOÃO GRILO: PÍCARO DO NORDESTE, JUSTICEIRO DO SERTÃO
}

Me. João Evangelista do Nascimento Neto ${ }^{1}$

RESUMO: Se João Grilo tem nacionalidade incerta, já que habita o imaginário popular em diversos países, é no sertão nordestino que encontra acolhida. Em 1948, João Ferreira de Lima lança o cordel Proezas de João Grilo. No texto, o personagem ganha nascimento, infância e adultez. A vida do personagem assemelha-se à de tantos sertanejos, e, por isso, em João Grilo, a picardia ganha ares requintados. Se o pícaro clássico age tão-somente para garantir o direito à vida, João Grilo alia tal necessidade com o mais puro prazer de burlar os outros. Desde a infância, aprendera a rir dos outros. João, em cada ato, torna-se exemplo e imagem de uma camada social abandonada à própria sorte. Cada vingança de Grilo é uma vingança do povo que representa contra os poderosos e emissários do governo. Rir das ações do pícaro não é somente aprender a rir da sua própria situação, mas também crer que é possível vencer o nobre, sendo plebeu; subjugar o forte, sendo fraco; dominar o rico, sendo pobre. As atitudes de João Grilo diminuem o fosso entre os mais necessitados e os abastados. Sua luta é com as palavras. É a única arma que o humilde possui, sua voz. É certo que ela é fraca, quase inaudível aos ouvidos do poder constituído, mas, ainda assim, é uma palavra cortante, afiada, capaz de questionar, boa para insurgir contra os poderosos. É essa a arma de João Grilo. Este trabalho, pois, discute a construção da figura do João grilo, retratado nos folhetos como um justiceiro social, sua descrição física, psicológica, bem como a compreensão de seus atos enquanto meio de insubmissão das classes subalternizadas diante das injustiças que lhe são acometidas. E é por intermédio das palavras de teóricos como Zumthor (1993), Haurélio (2010), e Araújo (1992) que o discurso do Amarelo é ouvido, questionado, proferido, analisado.

PALAVRAS-CHAVE: Grilo; Cordel; Pícaro; Vingador; Nordeste.

ABSTRACT: If you João Grilo is uncertain nationality, since inhabits the popular imagination in several countries, is in the northeastern hinterland that is upheld. In 1948, João Ferreira de Lima launches Proezas de João Grilo. In the text, the character gains birth, childhood and adulthood. The character's life resembles that of many country people, and therefore, in João Grilo, the mischief wins exquisite airs. If the rogue classic acts merely to guarantee the right to life, Grilo combines this need with the purest pleasure to deceive others. Since childhood, learned to laugh at others. João, in every act, becomes an example and picture of a social layer abandoned to their fate. Each revenge is a vengeance that represents the people against the powerful emissaries and government. Laugh at the actions of the rogue is not only learn to laugh at her own situation, but also believe that it is possible to win the noble; subdue the strong; dominate the rich. The attitudes of João Grilo decrease the gap between the most deprived and affluent. Your fight is with words. It is the only weapon that has the humble, his voice. Admittedly it is weak, almost inaudible to the ears of the authorities, but still, it's a word biting, sharp, able to question, good to stand against the powerful. This is the weapon of João Grilo. This paper therefore discusses the construction of the figure of João Grilo, pictured in the brochures as a vigilante social, physical description, psychological as well as understanding their actions as a means of insubordination of the subaltern classes the injustices that are affected. And it is

\footnotetext{
${ }^{1}$ Mestre em Literatura e Diversidade Cultural pela Universidade Estadual de Feira de Santana (UEFS). Cursa o Doutorado em Letras pela Pontifícia Universidade Católica do Rio Grande do Sul (PUCRS). É docente da área de Literatura da Universidade do Estado da Bahia (UNEB).
} 
through the words of theorists like Zumthor (1993), Haurélio (2010) and Araujo (1992) that the Amarelo' speech is heard, asked, given, analyzed.

KEY WORDS: Grilo; Cordel; Pícaro; Avenger; Northeast.

No princípio era a palavra, no começo das eras, na origem do homem, o texto oral reinava soberano, ditava as regras, estabelecia as ordens, forjava os desígnios. Mas chegou o tempo em que o ser humano inventou outro meio de comunicação, e por entre pedras, peles, papiros e papéis, criou a escrita. Aos poucos, esta foi enraizando-se no seio da humanidade, estabelecendo seu espaço, anteriormente pertencente à oralidade. A escrita procurou expulsar a palavra proferida, sua irmã mais velha, banir a fala para sempre, mas aí já era tarde.

A palavra-força promove sempre encontros com o leitor, sejam eles coletivos ou pessoais. Não há vazios textuais que não possam ser preenchidos pelo ouvinte, pelo leitor. Os vazios significam, simbolizam, dizem. É a palavra que proporciona, levando o leitor por caminhos a serem explorados. Por entre fissuras abertas na selva de significados, ou entre fendas que cortam avenidas de saberes, o vocábulo-performance é o guia de um leitorouvinte, que não se contenta em receber pacotes de conhecimentos prontos, enclausurados em fôrmas. Esse leitor-ouvinte, ou ouvinte-leitor, estabelece suas relações, compara as versões que ele próprio cria, revê conceitos, recria imagens:

\footnotetext{
O texto vibra; o leitor o estabiliza, integrando-o àquilo que é ele próprio. Então é ele que vibra, de corpo e alma. Não há algo que a linguagem tenha criado nem estrutura nem sistema completamente fechados; e as lacunas e os brancos que aí necessariamente subsistem constituem um espaço de liberdade: ilusório pelo fato de que só pode ser ocupado por um instante, por mim, por você, leitores nômades por vocação (ZUMTHOR, 2007, p. 53).
}

Quando se cala uma voz, a palavra constrói frestas para falar. Através dessas fissuras criadas entre a escrita e a oralidade, intituladas aqui de "frestas discursivas", surgem textos simbióticos que divergem de teorias que versam acerca de cultura letrada e de cultura popular. Por picadas de outrora, transformadas agora em estradas largas, é que surgiu a literatura de cordel no Brasil. Instrumento de divergência entre pesquisadores, a literatura de folhetos é vista, ora como devedora da cultura lusitana, ora com uma voz própria e caligrafia tupiniquim.

No sertão de chão duro e quase impermeável à chuva, a palavra-performance fez sua morada, fincou suas raízes, fez dele sair seus brotos, que se transformaram em galhos firmes de uma árvore frondosa que é a cultura nordestina. Um desses galhos, que dá boa sombra aos que por essa árvore passam, é a literatura de cordel (HAURÉLIO, 2010). 
A palavra-força é tomada por João Grilo, quando da sua chegada em solo brasileiro. Assim como um dia os homens roubaram o fogo dos deuses, Grilo, detentor da fala das camadas populares, apropria-se do discurso dos poderosos a fim de que, fundidos os dois, surja um texto intenso, imbuído de críticas sociais, permeado de escárnio e desejo de sobrevivência. Esse capítulo da vida do personagem em solo brasileiro deu-se em terras nordestinas, mais especificamente no ano de 1932, com "a publicação de Palhaçadas de João Grilo, de João Ferreira de Lima, na tipografia Athayde, no Recife" (HAURÉLIO, 2010, p. $67)$.

É no sertão nordestino que Grilo encontra acolhida. Sob o forte sol do sertão, renasce com outras características díspares da sua representação portuguesa. Em 1948, João Ferreira de Lima relança o cordel, batizado agora como Proezas de João Grilo. No texto, o personagem ganha nascimento, infância e adultez. A morte? Essa não é contada, pois simplesmente inexiste. Personagens, como João Grilo, não morrem jamais, pois renascem na memória dos ouvintes e leitores e nas obras produzidas sobre eles. Daí sua vida ser um eterno re-nascimento:

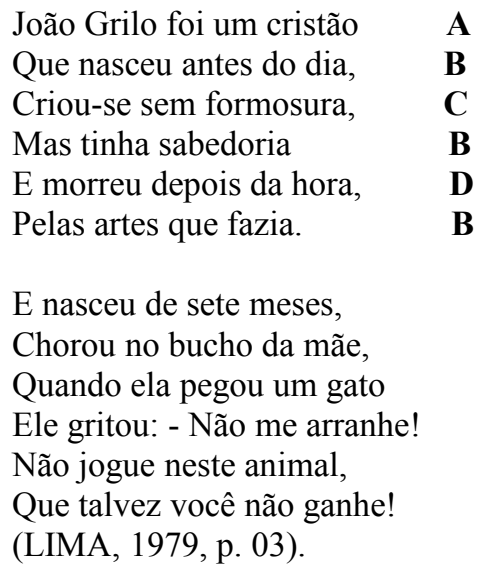

João Grilo é um ser especial, um ente único. Antes mesmo de nascer, eventos sobrenaturais prenunciavam que estava por vir uma criatura que transformaria o mundo. Desprovido de beleza física, superabundava em inteligência. A primeira sextilha, com rima ABCBDB, apresenta o Amarelo em tom profético, anunciando nascimento e morte. A voz narrativa, ao fundir ao discurso solene um ar jocoso, sugere que transformações são essas que o personagem faria vir à tona: sua presença seria incômoda onde estivesse e sua inteligência confundiria os sábios. No fim da primeira sextilha, há o prognóstico de que teria condições, 
pela sua sabedoria, de enganar até mesmo a morte, fato que será narrado por Ariano Suassuna em seu Auto da Compadecida.

O título de cristão que recebe, remete à religiosidade do povo do sertão, local onde o catolicismo popular encontrou espaço para fincar seus pilares. Mentiroso, trapaceiro, enganador. Diante de todas essas adjetivações, Grilo é cristão justificado, já que a maioria de suas atitudes revela o forte desejo de um nordestino em sobreviver em meio à seca da região e à aridez de ações do governo e das demais instituições oficiais.

Antes de nascer, já fazia prodígios, como falar no ventre da mãe. Parecia saber, o ardiloso, que nessa vida, o pobre não pode contar com a sorte para enriquecer, nem mesmo apostando no jogo do bicho. Resta-lhe, portanto, a astúcia para driblar a fome e a morte todos os dias. Mas isso não o intimida. Grilo, ansioso para vir enfrentar a vida e dar trabalho a ela, nasce dois meses antes do previsto. A noite de sua chegada foi marcada por estranhos eventos:

\author{
Na noite que João nasceu, \\ Houve um eclipse na lua, \\ Detonou grande vulcão \\ Que ainda hoje continua; \\ Naquela noite correu \\ Um lobisomem na rua. \\ Assim mesmo ele criou-se \\ Pequeno, magro e sambudo, \\ As pernas tortas e finas, \\ A boca grande e beiçudo. \\ No sítio onde morava, \\ Dava notícia de tudo \\ (LIMA, 1979, p. 03).
}

O nascimento de João Grilo apresenta traços que se assemelham ao de Jesus. Assim como, durante o nascimento de Cristo, a natureza se manifesta, estranhos eventos marcam a vinda do personagem nordestino: um eclipse lunar, um vulcão em erupção e um lobisomem são evidências que aquele dia é especial e que, da mesma maneira que o mundo seria transformado pela vinda do Filho de Deus, o sertão seria revirado pelas ações de Grilo. Não há pretensão em transformar o personagem em divindade, nem de aproximá-lo da figura de Jesus, mas em ser seu contraponto. Se de um lado, tem-se Emanuel e seu sério discurso de salvação da humanidade, do outro, aparece João Grilo e seu discurso chistoso de salvação de si mesmo: a seriedade do discurso da religião versus a pilhéria da linguagem popular. Mas é na hora da necessidade que o pícaro reconhece sua pequenez diante do Salvador. Aí utiliza de 
suas artimanhas para garantir a benevolência do Manuel do catolicismo popular, que também se diverte com as palhaçadas do pícaro e percebe que a vida é muito mais fácil de ser vivida com doses de humor.

As características físicas de João Grilo afastam-no de qualquer previsão de vida longa ou de êxito: sem beleza física, era de baixa estatura, franzino e barrigudo, enfim, representava o menino que, desnutrido, não conseguira crescer adequadamente. Sua vida é, como de tantos sertanejos, um milagre desses que só existem no Nordeste. A barriga grande é causada pela esquistossomose, o que dá um ar risível, já que sua descrição aponta para uma criança magra que carrega o peso de uma barriga repleta de vermes conseguidos por ingerir alimentos mal lavados e água de cacimbas, sem tratamento. Daí a alcunha de Amarelo, como muitos outros pequenos nordestinos. Contra todas as previsões, João Grilo cresce irrequieto. Na região onde morava, cresceu, fazendo-se conhecido pelas suas intromissões nos mais diversos assuntos. É desde pequeno que Grilo constrói sua fama de pícaro.

Em João Grilo, a picardia ganha ares requintados. Se o pícaro clássico age tãosomente para garantir o direito à vida, João Grilo alia tal necessidade com o mais puro prazer de burlar os outros. Desde a infância, aprendera a rir dos outros. Nascera para tal. Suas aventuras parecem não ter fim: o quase afogamento de um vaqueiro na cheia do rio, a garapa com rato morto oferecida ao padre, o penico da mãe oferecido como cuia de água ao vigário, a pretensa confissão que gerou a nudez do cura e a vingança contra o português vendedor de ovos são algumas de suas peripécias registradas no cordel.

Como perdera o pai aos sete anos, a sua mãe era a única referência familiar que possuía. Transformara-se, desde cedo, no homem da casa com a morte do pai. Era preciso cuidar da sua genitora. É desse modo que a escola torna-se um elemento secundário na vida de João Grilo, tendo frequentado o ambiente educacional dos sete aos dez anos somente. Sua sabedoria, portanto, é advinda de lugares não formais de saber. Por isso, também, a escola não o atraiu. Em três anos, percebeu que o seu saber não cabia nas quatro paredes daquele prédio que guardava o conhecimento oficial. Ao questionar o professor dos saberes práticos, não obteve resposta:

$\begin{array}{ll}\text { João Grilo, em qualquer escola, } & \text { A } \\ \text { Tinha do povo a atenção, } & \text { B } \\ \text { Passava quinau no mestre, } & \text { C } \\ \text { Nunca faltou com a lição. } & \text { B } \\ \text { Era um tipo inteligente - } & \text { D } \\ \text { No futuro e no presente, } & \text { D } \\ \text { João dava interpretação. } & \text { B }\end{array}$




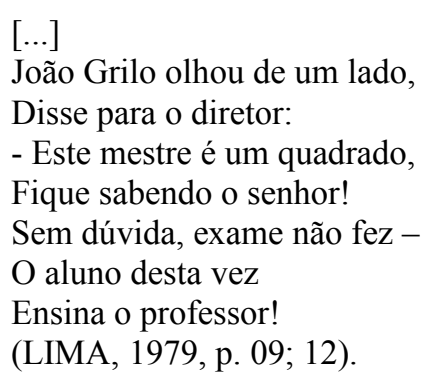

Nessa septilha, com rima em ABCBDDB, o narrador explicita que Grilo já detinha o conhecimento necessário para sobreviver, o saber da vida. É das ruas, dos campos e do contato com as pessoas que nasce o saber do Amarelo, uma ciência do riso, um conhecimento da alegria mesmo em face dos obstáculos. Quer seja enfrentando ladrões, ou mesmo os desafios de um sultão, João, em cada ato, torna-se exemplo e imagem de uma camada social abandonada à própria sorte. Cada vingança de Grilo é uma vingança do povo que representa contra os poderosos e representantes do governo. Rir das ações do pícaro não é somente aprender a rir da sua própria situação, mas também crer que é possível vencer o nobre, sendo plebeu; subjugar o forte, sendo fraco; dominar o rico, sendo pobre:

Humilhando, pelo riso, os seus algozes, o anti-herói realiza uma catarsis reveladora do caráter e disposição de luta e resistência do povo de que é símbolo. Justamente por representar a gente simples e, em consequência os sofrimentos e mágoas das populações oprimidas é que o herói se identifica como o flagelo do Poder. Por isso todas as formas de poder no Nordeste são atingidas [...] (ARAÚJO, 1992, p. 7-8).

As atitudes de João Grilo diminuem o fosso entre os mais necessitados e os abastados, mesmo que, para isso, seja preciso recorrer ao fantástico, como no seu encontro, na caatinga, com ladrões de Meca que haviam roubado no Egito. Aqui, todas as distâncias são reduzidas, a fim de que o Amarelo possa colocar em prática a máxima que "ladrão que rouba ladrão, tem cem anos de perdão". Com uma ação simples, veste-se com um lençol branco, deita em um caixão, finge ser um fantasma, afugenta os bandidos, e ainda fica com o soldo da ação dos malfeitores. É perdoado pela mãe, ao chegar a casa, pois "os fins justificam os meios”, outra máxima praticada pelo personagem.

No embate de Grilo com o sultão Bartolomeu do Egito, o seu dom de adivinhação é posto em xeque pela majestade que o ameaça de morte caso não consiga resolver as doze questões propostas. Como Hércules, é preciso que o Amarelo delibere sobre os doze trabalhos do Sultão. Mas, por não ter um corpo hercúleo, sua luta é com as palavras. É a única arma que o humilde possui, sua voz. É certo que ela é fraca, quase inaudível aos ouvidos do poder 
constituído, mas, ainda assim, é uma palavra cortante, afiada, capaz de questionar, boa para insurgir contra os poderosos. É essa a arma de João Grilo. Com ela, o nordestino adivinhão acerta as esfíngicas charadas, por conhecimento, as oito primeiras, e por sorte, as duas seguintes.

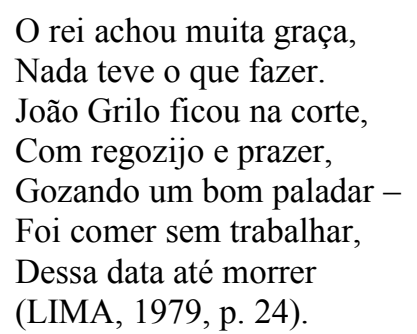

Grilo não completa os doze trabalhos, pois somente dez questões lhe são apresentadas pelo Sultão. Isso é o bastante para que ele consiga a confiança do rei e tenha a sua vida transformada. Passa de pobre a rico e realiza o sonho de todo pobre sertanejo, não precisar ganhar o sustento pelo suor do seu trabalho. A septilha supracitada atesta que, do palácio, o Amarelo não saiu mais, aproveitando a boa vida conseguida até a sua morte. É claro que o narrador não fala, no entanto, na segunda vida do farsesco, outra peculiaridade do personagem a ser tratada por Suassuna em sua obra. Até a morte, a primeira, Grilo contentou-se em ficar na corte, regalando-se com as mordomias recebidas, mas é certo que depois ele pulou, como grilo que é, por outros caminhos, conhecendo outras realidades, experimentando outras aventuras.

João Grilo brasileiro assume a função de magistrado do Egito. Utiliza a sagacidade que possui para "adivinhar" as pendências a ele trazidas. Nas Proezas de João Grilo, o personagem decide residir no palácio e mais, assume importante cargo de legislador. Semelhante ao patriarca José, no Egito, que passou de escravo condenado a governador, por ordem do Sultão, e também em terras egípcias,

\footnotetext{
Todas as proezas do reino Era João que deslindava. Qualquer pergunta difícil Ele sempre decifrava. Julgamentos delicados, Problemas muito enroscados, O João Grilo desmanchava (LIMA, 1979, p. 25).
}

Grilo é metamorfoseado de pobre desconhecido em respeitado juiz. É a vitória do saber popular sobre o valor das aparências. Dessa forma, Grilo fazia sua justiça prevalecer 
sobre os menos favorecidos. Conhecedor dos problemas dos mais humildes e da capacidade dos poderosos em rebaixar os mais pobres, o pícaro encarna a figura de defensor dos necessitados num claro embate de classes. Nessa luta, por mais erros que as pessoas das camadas populares cometam, são abonados por uma conjuntura opressora que as leva a agir desse modo. Por tal pensamento, delibera favorável a um mendigo contra um duque. Acusado pelo nobre de ter furtado o vapor da galinha que seu cozinheiro preparava, o mendigo, impelido pela fome, confessa ter colocado o pão apenas no ar quente a fim de saciar seu apetite. Esdrúxula história, o riso surge pelo teor da denúncia, mas por trás dela, há ricos oprimindo pobres, negando-lhes o direito de viver, cerceando-lhes os direitos básicos de sobrevivência, impedindo-lhes de alimentar-se. Mas se é esquisita a questão, isso pede uma resolução tão exótica quanto a pendência trazida aos ouvidos de João Grilo: o juiz coloca moedas de ouro na mochila do mendigo e pede que ele a balance, fazendo as moedas tilintarem. Se provar o vapor é crime, o pagamento pode ser dado pelo alarido das moedas, odor por som, um sentido por outro. Com uma decisão salomônica, Grilo resolveu a questão, deixando o duque insatisfeito e o mendigo com as cinco coroas de prata. Enfim, os papéis inverteram-se: a justiça sorriu para os mais fracos:

A forma como João Grilo resolve a questão demonstra que a perseguição aos humildes não passa desapercebida à trovadoresca do cordel, cuja sátira responde às inquietações do homem comum pelo látego da malícia, da picardia, da malandragem (ARAÚJO, 1992, p. 14).

Se, no mundo prático, está difícil visibilizar direitos iguais para todos, no cordel sobre João Grilo, ela se faz presente com a atuação do pícaro que, mesmo rico, continua a agir conforme seu pensamento de justiça. Mas a justiça de um pícaro não transita pelos mesmos vieses que a oficial. Ela se dá da forma como o personagem aprendeu nas suas lutas diárias, passando por cima de códigos de conduta, esquecendo-se de leis morais, regras sociais e práticas jurídicas. Para o anti-herói, não basta lograr êxito em suas ações, elas precisam gerar o próprio riso, o riso de outros personagens e o riso dos seus admiradores.

A última aventura "grilesca" se passa em um reino de outro sultão. Por sua fama ter-se espalhado, é convidado, com honras de Estado, a fazer-se presente para ser aclamado por sua sabedoria e senso de justiça. Toda a corte se prepara para receber o grande João Grilo que se apresenta simplório, com as vestes remendadas e os sapatos furados. Para decepção do paço, aquele era o renomado juiz. Nesse enredo, a supervalorização das aparências é o mote utilizado para questionar os valores de uma sociedade baseada em futilidades, como roupas, 
calçados e acessórios. A moda, vista como vazia, é a simbologia de uma sociedade também oca. Por mais que os atributos de Grilo fossem cantados em prosa e em verso, era a sua aparência o que toda a corte aguardava. Em um mundo onde as vestes valem mais do que quem as usa, não pode haver justiça social. Em um lugar onde a preocupação central é o exterior, não sobrará tempo para o requinte das virtudes, o esmerilhamento dos valores pessoais ou o aperfeiçoamento do bem coletivo. Essa é a prova da história, mas desta vez, é João Grilo quem a propõe a todo o reino que está visitando.

Quando estava maltrapilho, fora maltratado, levado para alimentar-se na cozinha, longe dos membros da corte, separado do convívio com os nobres, sofreu injúrias e toda sorte de preconceitos. Então, veste-se com as roupas finas, que havia trazido em sua bolsa, e exibese diante do público no castelo. Para comoção geral, todos se regozijam com o João Grilo bem trajado, e reconhecem nele, agora, o grande juiz. O banquete, feito para ele, pode ser servido com todas as pompas, mas o Grilo legislador precisa, enquanto defensor da essência do ser humano sobre a sua aparência, levar as pessoas à reflexão. Assim,

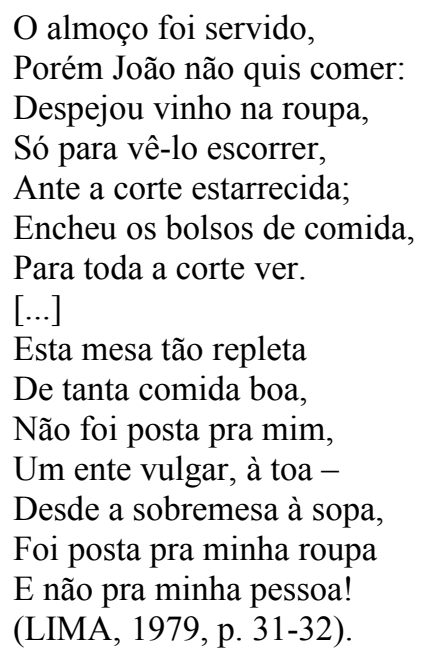

Como em uma fábula, o Grilo encerra sua estada na corte com uma lição de moral a ser seguida: não se pode medir a capacidade intelectual humana por aquilo que se veste, mas os atributos a serem venerados são a sabedoria e a caridade. A homenagem recebida não lhe dizia respeito, mas era para seus ricos trajes. Desse modo, a estes ele o repassava. O outrora pícaro agora se estabelece como um homem sapiente que, na maturidade, depois de ter passado privações e obtido riquezas, não mudou. Em seu cerne, havia o mesmo morador do sertão nordestino, que aprendera a ver o sofrimento alheio com o seu próprio sofrimento. 
A vingança é arma que o personagem usa como reparação dos males cometidos pelos poderosos contra ele; para tal, utiliza a inteligência, pois é destituído de força física. Cada ação premeditada possui a intenção de gerar o cômico. Não basta a vingança, ela precisa ridicularizar o algoz aos seus olhos, aos olhos do inimigo e, principalmente, às vistas do público-leitor, dos ouvintes e dos espectadores, estes que são os responsáveis pela divulgação e perpetuação das artimanhas do pícaro, seu representante e porta-voz.

Referências

ARAÚJO, Jorge de Souza. João Grilo: síntese e transparência do anti-herói popular. Em: Sitientibus. Feira de Santana: Universidade Estadual de Feira de Santana, v.6, n. 9, jan./jun. 1992. pp 5-19.

HAURÉLIO, Marco. Breve história da literatura de cordel. São Paulo: Claridade, 2010.

LIMA, João Ferreira de. Proezas de João Grilo. São Paulo: Luzeiro, 1979.

ZUMTHOR, Paul. Performance, recepção, leitura. 2. ed. Tradução de Jerusa Pires Ferreira e Suely Fenerich. São Paulo: Cosac Naify, 2007. 